\title{
Prognostic Value of the Circumferential Resection Margin in Esophageal Cancer Patients After Neoadjuvant Chemoradiotherapy
}

\author{
J. B. Hulshoff, BSc ${ }^{1}$, Z. Faiz, MD' ${ }^{1}$, A. Karrenbeld, $\mathrm{MD}^{2}$, G. Kats-Ugurlu, MD ${ }^{2}$, J. G. M. Burgerhof, $\mathrm{MSc}^{3}$, \\ J. K. Smit, MD, PhD ${ }^{1}$, and J. Th. M. Plukker, MD, PhD $^{1}$
}

${ }^{1}$ Department of Surgical Oncology, University of Groningen, University Medical Center Groningen, Groningen, The Netherlands; ${ }^{2}$ Department of Pathology, University of Groningen, University Medical Center Groningen, Groningen, The Netherlands; ${ }^{3}$ Department of Epidemiology, University of Groningen, University Medical Center Groningen, Groningen, The Netherlands

\begin{abstract}
Background. Circumferential resection margins (CRM) for esophageal cancer (EC), defined by the College of American Pathologists (CAP; $>0 \mathrm{~mm}$ ) or the Royal College of Pathologists (RCP; $>1 \mathrm{~mm}$ ) as tumor-free (R0), are based on a surgery-alone approach. We evaluated the usefulness of both definitions in current practice with neoadjuvant chemoradiotherapy (nCRT).

Methods. CRMs were measured in 209 patients (104 with nCRT) with locally advanced EC after transthoracic esophagectomy. Local recurrence and cancer related death were scored as events. Patients were followed for at least 2 years or until death. Prognostic factors $(P<0.1$ in univariate analyses) for 2-year disease-free survival (DFS) and local recurrence-free survival (LRFS) were incorporated in multivariate Cox regression analyses. Both CRM measurements were analyzed separately and prognostic cutoff values $(0-1.0 \mathrm{~mm})$ were assessed in both groups.

Results. Independent prognostic factors $(P<0.05)$ for 2 year DFS were tumor length, lymph node ratio, angioinvasion, and CAP R0 in the surgery-alone group and $\mathrm{pN}$ stage $(P<0.01)$ in the nCRT group. Prognostic factors
\end{abstract}

Presented at the SSO annual meeting 2015 and the ASCO GI 2015.

J. B. Hulshoff has controlled over data.

(C) The Author(s) 2015. This article is published with open access at Springerlink.com

First Received: 27 May 2015;

Published Online: 28 August 2015

J. Th. M. Plukker, MD, PhD

e-mail: j.t.m.plukker@umcg.nl
$(P<0.05)$ for 2 -year LRFS were CAP, lymph node ratio, and tumor length in the surgery-alone group, and CAP and grade in the nCRT group. Optimal CRM cutoff values between 0.0 and $0.2 \mathrm{~mm}$ were prognostic for 2-year DFS in the surgery-alone and at $0.3 \mathrm{~mm}$ for the nCRT group.

Conclusions. nCRT affected the CRM cutoff values. After nCRT, the CRM R0 according to the CAP was only prognostic for 2-year LRFS. However, in the surgery-alone group, it was prognostic for both the 2-year DFS and LRFS.

Even with neoadjuvant chemoradiotherapy (nCRT), the overall 5-year survival rate after esophagectomy remains relatively low at $47 \%$ in patients with locally advanced esophageal cancer (EC). ${ }^{1} \mathrm{~A}$ strong prognostic indicator after a curative intended esophagectomy is the circumferential resection margin (CRM), rendered as microscopic tumor-free (R0) or tumor-positive (R1). ${ }^{2-8}$ Commonly used definitions of a circumferentially R0 resection are those of the College of American Pathologist (CAP; CRM $>0 \mathrm{~mm}$ ) and the Royal College of Pathologists (RCP; CRM $>1 \mathrm{~mm}) .{ }^{9,10}$ After nCRT, the optimal CRM may be influenced by tumor downsizing, which facilitates a R0 resection.

The optimal CRM cutoff point after nCRT has not been defined yet. Recently, two meta-analyses showed a significant association of a positive CRM according to both definitions with poor outcome, which was even worse in patients with stage T3 disease or after nCRT. ${ }^{11,12}$ However, these studies did not assess which CRM definition was more powerful after nCRT, while contradictory results after nCRT were reported in three other studies without a 
surgery-alone control group. ${ }^{13-15}$ Two studies, with only squamous cell carcinoma, showed a significant better survival rate in patients with a CRM $>1 \mathrm{~mm}$, whereas no survival benefit was observed in R0 resections according to the CAP and RCP in a study with only T3 stage adenocarcinomas. ${ }^{13-15}$

We assessed the optimal CRM cutoff point and the prognostic value of $\mathrm{R} 0$ resections according to the $\mathrm{CAP}$ and RCP criteria in EC patients treated either with nCRT or surgery alone.

\section{PATIENTS AND METHODS}

Data collection of this explorative retrospective study was provided from a prospective maintained database of EC patients according to the national guidelines and the rules approved by the local ethical commission (www. ccmo.nl). We included only patients with a locally advanced curatively resectable EC (stage II-III) treated between 1997 and 2013, in whom the CRM was adequately assessed by our expert pathologists. Of the patients treated with nCRT $(n=127)$ between 2005 and 2013, 23 were excluded because of the following criteria: incomplete medical records $(n=0)$, postoperative mortality (death within 90 days or in-hospital, $n=10$ ), progressive disease within 3 months after surgery or microscopic irradical (R1; tumor cells $<1 \mathrm{~mm})$ longitudinal margins $(n=0)$ or follow-up $<24$ months $(n=13)$. Based on these exclusion criteria, a reference group of surgery-alone treated patients $(n=105)$ was constructed. Patients and tumor-related factors were matched and were equally distributed between both groups (Table 1).

Tumors staged according to the 6th TNM edition were recoded into the 7th edition. ${ }^{16,17}$ Before $2000(n=11)$, staging consisted of endoscopic ultrasonography (EUS) with fine-needle aspiration (FNA), computed tomography (CT) of the neck, thorax, and abdomen and occasionally 18-F-fluorodeoxyglucose positron emission tomography (FDG-PET, $n=8$ ). After 2000, a standard FDG-PET was added, which was replaced by FDG-PET/CT after 2009 . Two weeks after nCRT, patients were restaged with a CT thorax and abdomen.

\section{Treatment}

All patients underwent a transthoracic esophagectomy with en bloc dissection of regional mediastinal and abdominal (including the celiac trunk region) lymph nodes. Patients with nCRT were treated according to the Dutch Chemoradiotherapy for Oesophageal Cancer Followed by Surgery Study (CROSS) regimen, consisting of intravenous paclitaxel $\left(50 \mathrm{mg} / \mathrm{m}^{2}\right)$ and carboplatin (AUC: $2 \mathrm{ml} / \mathrm{min}$ ), administered five times during a 5-week concurrent radiation period (41.4 Gy/23 fractions of $1.8 \mathrm{~Gy}) .{ }^{1}$ Before 2009, patients received nCRT based on their participation in the CROSS trial, from 2009 onwards nCRT became standard of care for locally advanced EC patients (T1-4aN1-3, T24 aNO-3; $n=75$ ).

\section{Pathology}

Resected specimens were examined according to a standardized protocol by two specialized gastrointestinal pathologists. The resected specimen was pinned on a Styrofoam plate by the surgeon, enabling accurate pathological assessment of the marked Clinical Tumor Volume and Gross Tumor Volume areas in patients treated with nCRT. ${ }^{18}$ CRM was measured according to the method of Quirke; the specimens were inked with Indian ink and fixed in formalin during $24 \mathrm{~h}^{6}$ The specimens were sliced into transverse cross-sections of $0.5 \mathrm{~cm}$ for macroscopic assessment and sampling of at least two sections with the smallest CRM. ${ }^{2}$ The CRM was microscopically assessed on hematoxylin and eosin stained samples in tenths of millimetres. Furthermore, the pT-stage, pN-stage, the lymph-node ratio ( $>0.2$ metastatic lymph node ratio), number of positive lymph nodes $(>4)$, histological tumor type, tumor grade, angioinvasion, and perineural tumor growth were assessed.

\section{Follow-up}

Patients were followed for at least 2 years or until death, every 3 months during the first year after surgery, every 6 months in the second year, and every year thereafter for the next 10 years. Tumor recurrence was defined as histo/cytologically proven, suspected radiological imaging, or clinically evident recurrence. Local recurrence included recurrent disease at the anastomotic site or in the original tumor/mediastinal bed.

\section{Statistical Analysis}

Distribution of continuous patient characteristics was reported as median [interquartile range] and categorical variables were reported in numbers and percentages. The patients groups were compared with the Mann-Whitney test for continuous variables and $\chi^{2}$ or Fisher exact test for categorical response variables. Kaplan-Meier curves and log-rank test determine the 5-year disease-free survival (DFS) and local recurrence-free survival (LRFS) of both CRM definitions. Prognostic values of all variables for 2year DFS were assessed with univariate Cox regression analysis. Factors within the univariate analysis were: age, 
tumor type, and grade (G1-2 vs. G3-4), clinical T and N stage, tumor length $(>5 \mathrm{~cm}$, measured endoscopic or with $\mathrm{CT}$ ), treatment type (nCRT or surgery alone), and pathologic outcome: $\mathrm{T}$ and $\mathrm{N}$ stage, number of $\mathrm{LN}$ metastases
$(>4)$, and metastatic lymph node ratio $(>0.2)$, perineural growth, and angioinvasion. Multivariate Cox regression was performed by incorporating all variables with a $P$ value $<0.1$ on univariate analysis. Both, the CAP $(\mathrm{CRM}>0 \mathrm{~mm})$

TABLE 1 Patient characteristics in the surgery-alone and neoadjuvant chemoradiotherapy (nCRT) groups

\begin{tabular}{|c|c|c|c|}
\hline & nCRT $(n=104)$ & Surgery alone $(n=105)$ & $P$ value \\
\hline Male & $79(76.0 \%)$ & $82(78.1 \%)$ & $0.714^{\mathrm{a}}$ \\
\hline Age (year), median (IQR) & $63(56-67)$ & $64(57-69)$ & $0.228^{\mathrm{b}}$ \\
\hline Histology & & & $0.382^{\circ}$ \\
\hline Adenocarcinoma & $88(84.6 \%)$ & $84(80 \%)$ & \\
\hline Squamous cell carcinoma & $16(15.4 \%)$ & $21(20 \%)$ & \\
\hline Tumor location & & & $0.654^{\mathrm{a}}$ \\
\hline Middle esophagus & $8(7.7 \%)$ & $12(11.4 \%)$ & \\
\hline Distal esophagus & $50(48.1 \%)$ & $49(46.7 \%)$ & \\
\hline GEJ & $46(44.2 \%)$ & $44(41.9 \%)$ & \\
\hline Tumor length $>5 \mathrm{~cm}$ & $59(56.7 \%)$ & $60(57.1 \%)$ & $0.695^{\mathrm{b}}$ \\
\hline cT-stage & & & $0.221^{\mathrm{a}}$ \\
\hline $\mathrm{T} 2$ & $16(15.4 \%)$ & $9(8.6 \%)$ & \\
\hline $\mathrm{T} 3$ & $83(79.8 \%)$ & $93(88.6 \%)$ & \\
\hline $\mathrm{T} 4 \mathrm{a}$ & $5(4.8 \%)$ & $3(2.9 \%)$ & \\
\hline cN-stage & & & $0.176^{\mathrm{a}}$ \\
\hline No & $27(26 \%)$ & $41(39 \%)$ & \\
\hline N1 & $50(48.1 \%)$ & $44(41.9 \%)$ & \\
\hline $\mathrm{N} 2$ & $22(21.2 \%)$ & $18(17.1 \%)$ & \\
\hline N3 & $5(4.8 \%)$ & $2(1.9 \%)$ & \\
\hline pT-stage & & & $<0.001^{\mathrm{C}}$ \\
\hline $\mathrm{Tx}$ & $1(1 \%)$ & & \\
\hline T0 & $21(20.2 \%)$ & & \\
\hline $\mathrm{T} 1$ & $22(21.2 \%)$ & & \\
\hline $\mathrm{T} 2$ & $14(13.5 \%)$ & $20(19 \%)$ & \\
\hline $\mathrm{T} 3$ & $46(44.2 \%)$ & $82(78.1 \%)$ & \\
\hline $\mathrm{T} 4 \mathrm{a}$ & $0(0 \%)$ & $3(2.9 \%)$ & \\
\hline pN-stage & & & $<0.001^{\mathrm{a}}$ \\
\hline No & $62(59.6 \%)$ & $28(26.7 \%)$ & \\
\hline N1 & $26(25.0 \%)$ & $34(32.4 \%)$ & \\
\hline N2 & $11(10.6 \%)$ & $25(23.8 \%)$ & \\
\hline N3 & $5(4.8 \%)$ & $18(17.1 \%)$ & \\
\hline Perineural growth & $22(21.2 \%)$ & $33(31.4 \%)$ & $0.084^{\circ}$ \\
\hline Angioinvasion & $22(21.2 \%)$ & $51(48.6 \%)$ & $<0.001^{\circ}$ \\
\hline Number of LN $(>4 \mathrm{LN}+)$ & $10(9.6 \%)$ & $32(30.5 \%)$ & $<0.001^{\mathrm{a}}$ \\
\hline Lymph node ratio $(>0.2)$ & $18(17.3 \%)$ & $50(47.6 \%)$ & $<0.001^{\circ}$ \\
\hline Follow-up mo, median (IQR) & $27.5(15.0-42.0)$ & $29(15.5-56.0)$ & $0.241^{\mathrm{b}}$ \\
\hline Tumor recurrence & $63(60.6 \%)$ & $75(71.4 \%)$ & $0.098^{\circ}$ \\
\hline Local recurrence & $17(16.3 \%)$ & $35(33.3 \%)$ & $0.005^{\circ}$ \\
\hline Death & $60(57.7 \%)$ & $83(79 \%)$ & $0.001^{\mathrm{a}}$ \\
\hline Tumor-related death & $54(51.9 \%)$ & $73(69.5 \%)$ & $0.009^{\mathrm{a}}$ \\
\hline CRM (mm), median (IQR) & $3.3(1.0-5.0)$ & $0.5(0-1.4)$ & $<0.001^{\mathrm{b}}$ \\
\hline 0 & $9(8.7 \%)$ & $27(25.7 \%)$ & $<0.001^{\mathrm{a}}$ \\
\hline $0-1$ & $13(12.5 \%)$ & $40(38.1 \%)$ & $<0.001^{\mathrm{a}}$ \\
\hline
\end{tabular}


TABLE 1 continued

\begin{tabular}{lcc}
\hline & nCRT $(n=104)$ & Surgery alone $(n=105)$ \\
\hline$>1$ & $82(78.8 \%)$ & $38(36.2 \%)$ \\
\hline$n C R T$ neoadjuvant chemoradiotherapy, $c T$ clinical T stage, $c N$ clinical lymph node stage, $p T$ pathological T stage, $p N$ pathologic lymph node \\
stage, $L N$ lymph node, $C R M$ circumferential resection margin, $C A P$ College of American Pathologists, $R C P$ Royal College of Pathologists, $I Q R$ \\
interquartile range \\
a $\chi^{2}$ test \\
b Mann-Whitney test \\
c Fisher exact test
\end{tabular}

and $\mathrm{RCP}(\mathrm{CRM}>1 \mathrm{~mm})$ definition entered the multivariate analysis separately. The prognostic value of $\mathrm{R} 0$ resections according to the RCP and CAP for the 2-year DFS and 2year LRFS was assessed with multivariate Cox regression analyses in both treatment groups. To assess the optimal cutoff value of the CRM on 2-year DFS, an explorative analysis was performed in both groups. Univariate analyses were undertaken to assess the prognostic value of all cutoff values (from 0.0 to $1.0 \mathrm{~mm}$ ). The observed interval is based on the assumption that the expected optimal CRM cutoff should be between 0.0 and $1.0 \mathrm{~mm}$. The Akaike Information Criterion (AIC), which quantifies the quality of a statistical model for a set of data was used to indirectly compare the prognostic value of the CAP and RCP model. ${ }^{19}$ It penalizes the number of explanatory variables by adding twice the number of variables in the model to the $-2 \log$ likelihood; in a formula AIC $=-2 \log$ likelihood $+2 \mathrm{k}$, in which $\mathrm{k}$ is the number of explanatory variables in the model. The model with the lowest AIC was considered to be most prognostic. The backwards likelihood ratio method was used in the Cox regression analysis. Analyses were performed with SPSS version 22.

\section{RESULTS}

Patient characteristics are summarized in Table 1. All nCRT patients with CAP-R1 resections ( $n=9 ; 8.7 \%)$ had stage pT3. Of the $27(25.7 \%) \mathrm{R} 1$ resections in patients treated with surgery alone, 24 had stage pT3, 1 had pT2, and 2 had stage pT4a disease. The median CRM differed significantly with 3.3 [interquartile range (IQR) 1.0-5.0] $\mathrm{mm}$ versus 0.5 (IQR 0-1.4) $\mathrm{mm}$ for the nCRT and surgeryalone group, respectively. The median follow up was 29.0 (IQR 15.5-56.0) months and 27.5 (IQR 15.0-42.0) in the surgery-alone and nCRT groups, respectively.

\section{Prognostic Value of the CAP and RCP Criteria}

Figure 1 displays the DFS of both treatment groups, with a R0 resection or involved CRM (R1 resection) according to CAP (Fig. 1a) and RCP (Fig. 1b). With the log-rank test, the CAP definition was prognostic for 5-year DFS in both the surgery $(P=0.008)$ and nCRT group $(P<0.001)$ and the RCP definition was prognostic in the nCRT group $(P<0.001)$ but not in the surgery group $(P=0.071)$. The 5-year DFS was not different $(P=0.131)$ between CAP R1 patients treated with or without nCRT but differed $(P=0.031)$ between patients with an RCP R1 resection in both groups.

Table 2 displays all prognostic factors with a $P<0.1$ on univariate analysis and Table 3 shows the multivariate Cox regression models containing either the CAP or RCP for 2 year DFS and LRFS in both groups. Independent prognostic factors for 2-year DFS in the surgery-alone group were tumor length $[P=0.006$, hazard ratio $(\mathrm{HR}) 2.68, \mathrm{CI}$ 1.33-5.43], lymph node ratio $(P=0.047$, HR 2.57 , CI 1.01-6.51), and CAP ( $P=0.012$, HR 0.41, CI 0.21-0.83). Independent prognostic factors for 2-year LRFS were lymph node ratio $(P=0.020$, HR 3.11 , CI $1.20-8.09)$, tumor length $(P=0.002$, HR 10.99, CI 2.49-48.43), and CAP $(P=0.004$, HR 0.27, CI 0.11-0.658). Both for 2-year DFS and LRFS, the model containing the CAP had a lower AIC than the RCP model and therefore was more prognostic.

The only independent prognostic factors for 2-year DFS in the nCRT group was the pN-stage (overall $P=0.004$ ), pN1 $(P=0.007$, HR 2.70, CI 1.31-5.59), and pN2-3 $(P=0.005, \quad$ HR $3.39, \quad$ CI 1.43-8.03). Both CAP $(P=0.001$, HR 0.06 , CI $0.01-0.31)$ and tumor grade $(P=0.008$, HR 16.91, CI 2.12-135.05) were prognostic for 2-year LRFS. For both 2-year DFS and LRFS, the multivariate regression model containing the CAP definition had a lower AIC and therefore was more prognostic.

\section{Optimal CRM after Surgery Alone and after $n C R T$}

CRM cutoff values of $0.0(P=0.012, \mathrm{HR}=0.41, \mathrm{CI}$ $0.21-0.83, \mathrm{AIC}=317.0), 0.1(P=0.045, \mathrm{HR}=0.50, \mathrm{CI}$ $0.25-0.98, \quad \mathrm{AIC}=320.0), \quad$ and $0.2 \mathrm{~mm} \quad(P=0.028$, $\mathrm{HR}=0.48$, CI 0.25-0.92, AIC = 318.8) were independent prognostic factors for 2-year DFS in the surgery-alone group. Based on the AIC, the 0.0-mm cutoff value (CAP) 
FIG. 1 Disease-free survival in patients treated with neoadjuvant chemoradiotherapy and surgery-alone, with circumferential microscopic tumor-free (R0) or involved resection margins (R1), according to a CAP $(0 \mathrm{~mm})$ and $\mathbf{b}$ RCP $(1 \mathrm{~mm})$

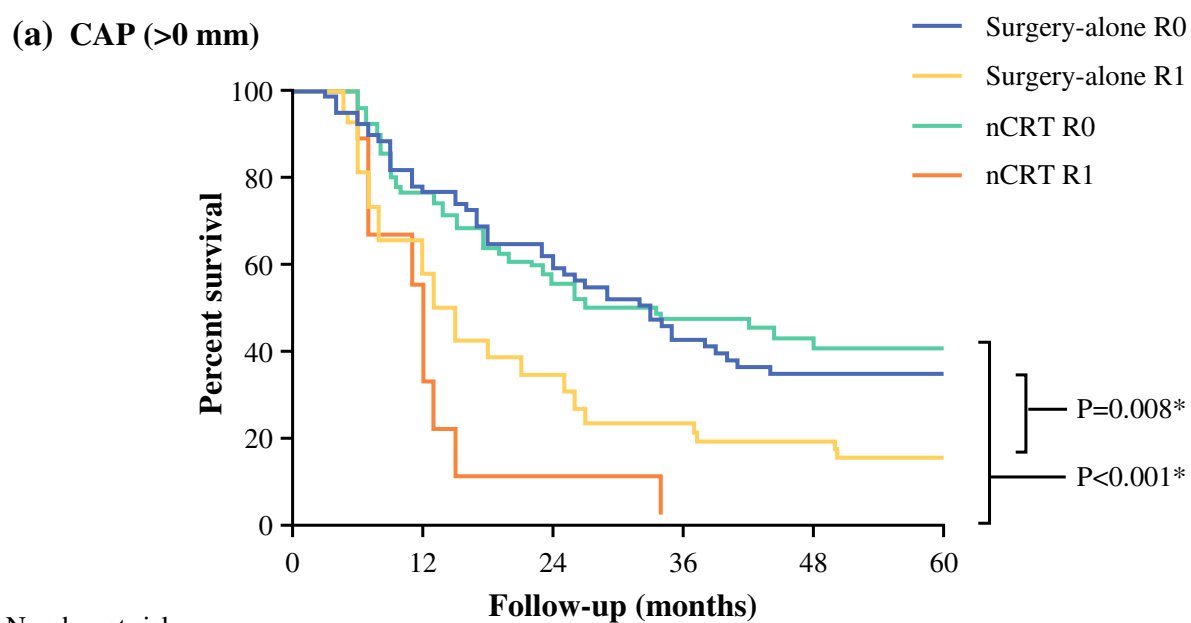

\begin{tabular}{lccccccc} 
Number at risk & & \multicolumn{5}{c}{ Follow-up (months) } \\
nCRT & R0 & 95 & 72 & 54 & 34 & 17 & 9 \\
& R1 & 9 & 5 & 1 & 0 & 0 & 0 \\
Surgery-alone & R0 & 78 & 59 & 44 & 27 & 20 & 18 \\
& R1 & 27 & 17 & 9 & 6 & 5 & 4
\end{tabular}

\section{(b) $\mathrm{RCP}(>1 \mathrm{~mm})$}

- Surgery-alone R0

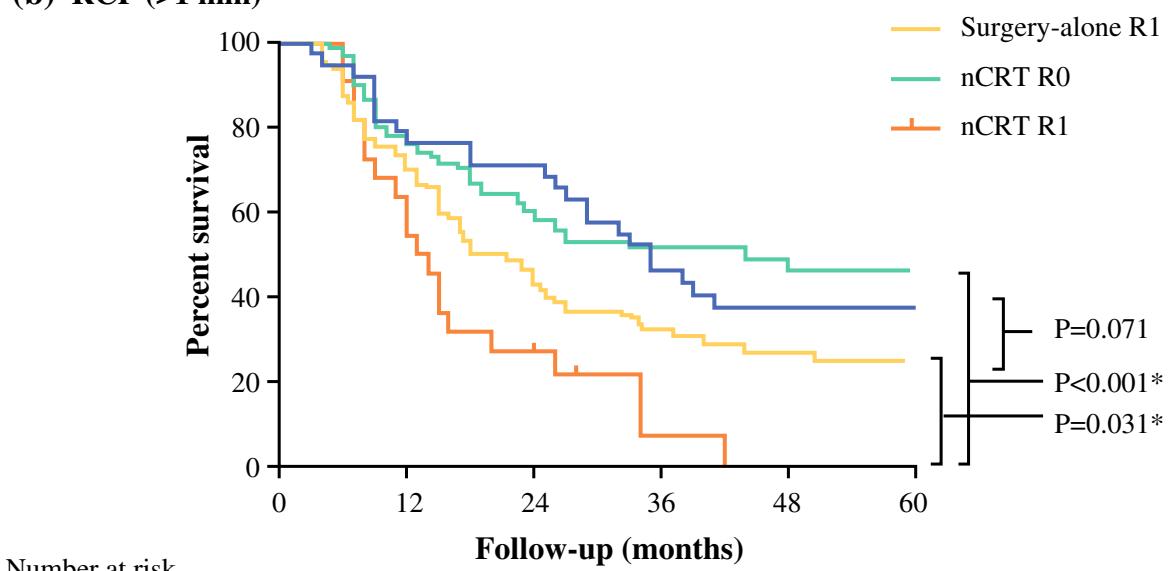

$\begin{array}{llllcccc}\text { Number at risk } & & & & & & & \\ \text { nCRT } & \text { R0 } & 82 & 63 & 49 & 33 & 17 & 9 \\ \text { Surgery-alone } & \text { R1 } & 22 & 14 & 6 & 1 & 0 & 0 \\ & \text { R0 } & 38 & 30 & 27 & 16 & 11 & 10 \\ & \text { R1 } & 67 & 46 & 26 & 17 & 14 & 12\end{array}$

was the most prognostic. However, in the nCRT group, the optimal cutoff value for 2-year DFS was $0.3 \mathrm{~mm}$ $(P=0.045, \mathrm{HR}=0.35$, CI $0.13-0.98$, AIC $=348.1)$.

\section{DISCUSSION}

The prognostic value of the circumferential margin (CRM) has been proven in EC patients after surgery alone, but its significance after neoadjuvant treatment is not well defined yet. This study conducted in stage II-III EC patients showed that both definitions of a free CRM were not prognostic for 2-year DFS in patients treated with nCRT. The CAP definition ( $>0 \mathrm{~mm}$ ), however, was an independent prognostic factor for 2-year DFS in the surgery-alone group and for LRFS in the nCRT and surgery-alone group. The optimal CRM cutoff value for 2-year DFS was 0.3 and between 0.0 and $0.2 \mathrm{~mm}$ in the nCRT and surgery-alone group, respectively.

This study is one of the first to assess the optimal cutoff value of the CRM after nCRT; previously published studies used either the RCP or CAP criteria of a free CRM. Although neoadjuvant treatment decreases the rate of $\mathrm{R} 1$ resection by transversal and sagittal tumor reduction, the induced fibrosis may contain different amounts of undetectable viable tumor cells. ${ }^{1}$ Therefore, the CRM assessment depends upon accurate histological examination of residual tumor, which might be related to tumor heterogeneity. CRM $>1 \mathrm{~mm}$ showed to be prognostic, but 
TABLE 2 Prognostic factors with $P<0.1$ on univariate analysis for disease-free and local recurrence-free survival in the surgery-alone and neoadjuvant chemoradiotherapy groups

\begin{tabular}{|c|c|c|c|c|c|c|}
\hline \multicolumn{7}{|c|}{ Surgery-alone group } \\
\hline & HR & $95 \% \mathrm{CI}$ & $P$ value & HR & $95 \% \mathrm{CI}$ & $P$ value \\
\hline pNO & 1.00 & & $0.001^{\mathrm{a}}$ & 1.00 & & $0.007^{\mathrm{a}}$ \\
\hline $\mathrm{pN} 1$ & 3.36 & $1.10-10.32$ & 0.034 & 4.08 & $0.87-19.26$ & 0.076 \\
\hline $\mathrm{pN} 2$ & 7.36 & $2.47-21.92$ & 0.000 & 3.39 & $0.62-18.56$ & 0.160 \\
\hline $\mathrm{pN} 3$ & 8.05 & $2.58-25.05$ & 0.000 & 11.54 & $2.48-53.79$ & 0.002 \\
\hline Tumor length & 2.23 & $1.14-4.34$ & 0.019 & 8.45 & $1.97-36.21$ & 0.004 \\
\hline Perineural growth & 2.00 & $1.11-3.60$ & 0.021 & & & NS \\
\hline Angioinvasion & 2.90 & $1.49-5.65$ & 0.002 & & & NS \\
\hline Number of LN & 4.01 & $2.21-7.26$ & $<0.001$ & 3.41 & $1.46-7.97$ & 0.005 \\
\hline Lymph node ratio & 3.96 & $2.08-7.55$ & $<0.001$ & 3.51 & $1.44-8.57$ & 0.006 \\
\hline CAP R0 & 0.45 & $0.25-0.82$ & 0.010 & 0.42 & $0.18-0.98$ & 0.044 \\
\hline RCP R0 & 0.46 & $0.23-0.91$ & 0.025 & 0.52 & $0.20-1.32$ & 0.168 \\
\hline \multicolumn{7}{|l|}{ nCRT group } \\
\hline & \multicolumn{3}{|c|}{ 2-year DFS } & \multicolumn{3}{|c|}{ 2-year LRFS } \\
\hline & HR & $95 \% \mathrm{CI}$ & $P$ value & HR & $95 \% \mathrm{CI}$ & $P$ value \\
\hline $\mathrm{cT} 2$ & 1.00 & & $0.013^{\mathrm{a}}$ & & & NS \\
\hline cT3 & 5.13 & $1.24-21.22$ & 0.024 & & & \\
\hline cT4a & 12.98 & $2.36-71.45$ & 0.003 & & & \\
\hline pT0 & 1.00 & & $0.054^{\mathrm{a}}$ & & & NS \\
\hline pT1 & 1.13 & $0.36-3.49$ & 0.837 & & & \\
\hline pT2 & 1.83 & $0.61-5.44$ & 0.279 & & & \\
\hline pT3 & 2.74 & $1.13-6.64$ & 0.025 & & & \\
\hline pNO & 1.00 & & $<0.001^{\mathrm{a}}$ & 1.00 & & $0.047^{\mathrm{a}}$ \\
\hline pN1 & 2.58 & $1.30-5.13$ & 0.007 & 0.56 & $0.07-4.65$ & 0.590 \\
\hline $\mathrm{pN} 2$ & 4.69 & $2.14-10.30$ & 0.000 & 5.37 & $1.28-22.55$ & 0.022 \\
\hline $\mathrm{pN} 3$ & 6.87 & $2.47-19.11$ & 0.000 & 7.31 & $0.76-70.88$ & 0.086 \\
\hline Perineural growth & 1.87 & $0.97-3.38$ & 0.062 & & & NS \\
\hline Angioinvasion & 1.81 & $0.98-3.53$ & 0.055 & & & NS \\
\hline Number of LN & 3.90 & $1.90-7.98$ & $<0.001$ & 8.00 & $1.92-33.25$ & 0.004 \\
\hline Lymph node ratio & 2.78 & $1.48-5.20$ & 0.001 & 4.31 & $1.25-14.95$ & 0.021 \\
\hline CAP R0 & 0.28 & $0.13-0.61$ & 0.001 & 0.42 & $0.18-0.98$ & $<0.001$ \\
\hline RCP R0 & 0.40 & $0.22-0.74$ & 0.003 & 0.30 & $0.09-1.06$ & 0.061 \\
\hline
\end{tabular}

DFS disease-free survival, $L R F S$ local recurrence free survival, $C I$ confidence interval, $c T$ clinical T stage, $c N$ clinical lymph node stage, $p T$ pathological T stage, $p N$ pathologic lymph node stage, $L N$ lymph node, $C R M$ circumferential resection margin, $R O$ tumor-free resection margin, $C A P$ College of American Pathologists, $R C P$ Royal College of Pathologists, NS not significant

a Overall $P$ value of the categorical variables

several studies reported conflicting results in patients treated with nCRT (Table 4). Chao et al. described a significantly better disease-free and disease-specific survival, whereas Liu et al. noted a significantly better overall survival (OS). ${ }^{13,14}$ However, Harvin et al. failed to prove a survival benefit after nCRT with respect to both CAP and RCP-CRM resections. ${ }^{15}$ This difference might be explained by the inclusion of different pathologic tumor types; Harvin et al. only included ypT3 or higher adenocarcinomas, whereas Chao et al. and Liu et al. included only patients with squamous cell carcinomas. ${ }^{13-15}$ In our study, histologic tumor type did not to affect the prognostic value of the CRMs for DFS and LRFS, although the number of squamous cell carcinomas in the nCRT group was rather small $(n=16)$. Inclusion of pathologic T3 tumors in determining the optimal CRM seems 
TABLE 3 Multivariate analysis of models containing the CRM definition according to the CAP (CRM $0 \mathrm{~mm}$ ) or the RCP (CRM $1 \mathrm{~mm}$ ), in the surgery-alone and neoadjuvant chemoradiotherapy groups

Surgery-alone group

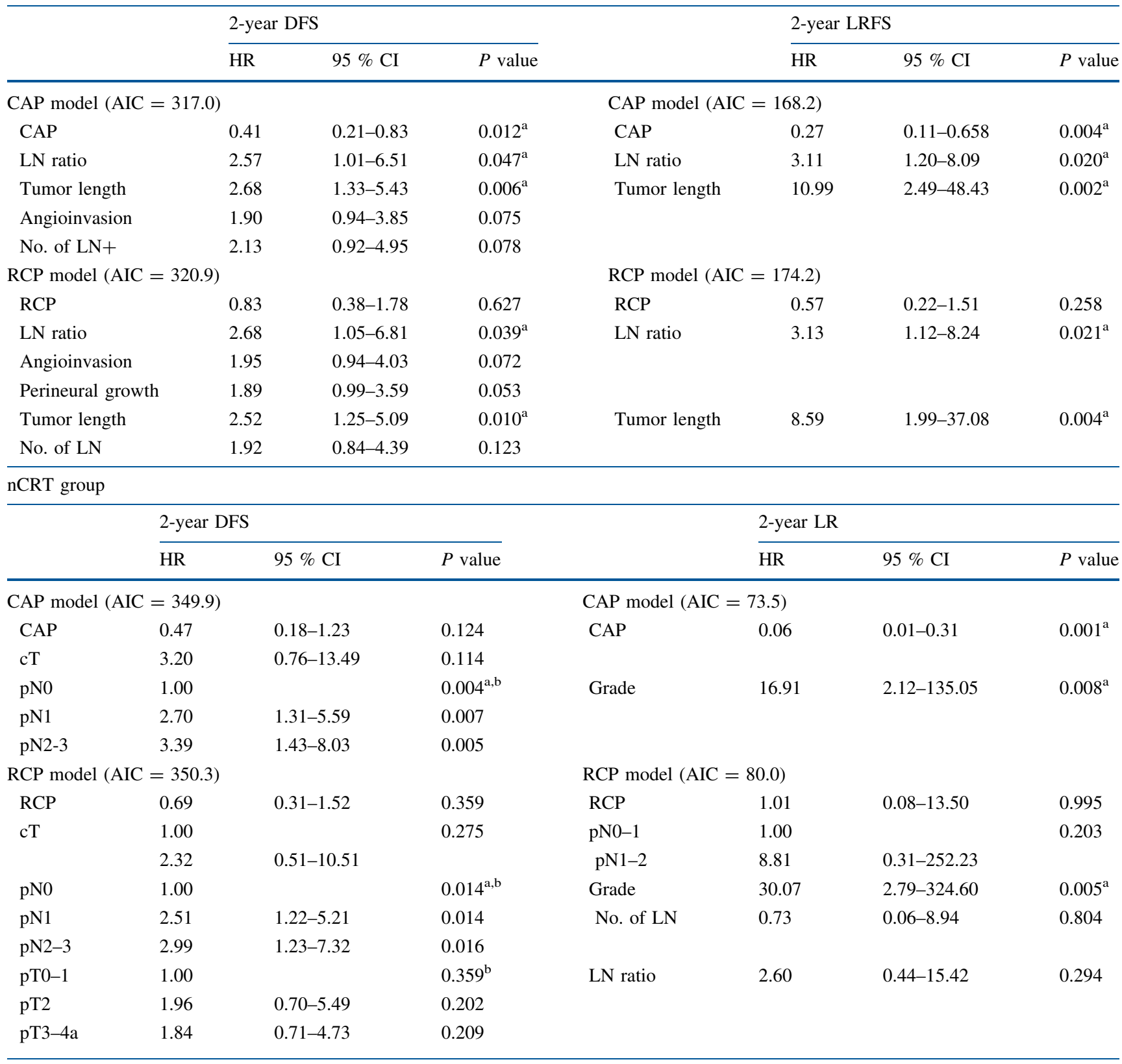

$D F S$ disease-free survival, $L R F S$ local recurrence-free survival, $C I$ confidence interval, $S C C$ squamous cell carcinoma, $c T$ clinical T stage, $c N$ clinical lymph node stage, $p T$ pathological $\mathrm{T}$ stage, $p N$ pathologic lymph node stage, $L N$ lymph node, $C R M$ circumferential margin, $R O$ tumorfree resection margin, CAP College of American Pathologists, $R C P$ Royal College of Pathologists

a Significant $(P<0.05)$

b Overall $P$ value of the categorical variables

comprehensible as circumferential R1 resections in pT2 tumors are generally considered to be caused by inadequate surgery. ${ }^{7,20,21}$ Moreover, Rao et al. stated that CRM involvement in the EC specimen is related to advanced disease rather than being an indicator of completeness of resection. ${ }^{4}$ In our study, only one patient staged as ypT2 disease had a R1 resection, due to extensive angioinvasive tumor growth within the CRM, which depends more on biologic aggressiveness rather than poor surgery. Another factor that might influence the CRM is the used surgical 
TABLE 4 Studies regarding prognostic value of the circumferential resection margin after neoadjuvant chemoradiotherapy

\begin{tabular}{|c|c|c|c|c|c|c|c|}
\hline Study (year) & Histology & Stage & Patients (n) & nCRT $(\%)$ & Outcome & CRM definition & $P$ value $^{\mathrm{a}}$ \\
\hline Thompson et al. ${ }^{23}$ & $\mathrm{AC}, \mathrm{SCC}$ & cT1-4 & 240 & $124(52 \%)$ & 5-year survival & $\mathrm{RCP}$ & NS \\
\hline \multirow[t]{3}{*}{ Chao et al. ${ }^{13}$} & \multirow[t]{3}{*}{ SCC } & \multirow[t]{3}{*}{ ypT3 } & \multirow[t]{3}{*}{151} & \multirow[t]{3}{*}{$151(100 \%)$} & LRFS & $\mathrm{RCP}$ & $<0.05$ \\
\hline & & & & & DFS & $\mathrm{RCP}$ & $<0.05$ \\
\hline & & & & & DSS & $\mathrm{RCP}$ & $<0.05$ \\
\hline \multirow[t]{2}{*}{ Harvin et al. ${ }^{15}$} & \multirow[t]{2}{*}{$\mathrm{AC}$} & \multirow[t]{2}{*}{ ypT3 } & \multirow[t]{2}{*}{160} & \multirow[t]{2}{*}{$160(100 \%)$} & OS, DFS, LRFS & CAP & NS \\
\hline & & & & & OS, DFS, LRFS & $\mathrm{RCP}$ & NS \\
\hline \multirow[t]{2}{*}{ Reid et al. ${ }^{25}$} & \multirow[t]{2}{*}{ AC SCC } & \multirow[t]{2}{*}{ cT1-4 } & \multirow[t]{2}{*}{269} & \multirow[t]{2}{*}{$42(16 \%)$} & DFS & $\mathrm{RCP}$ & $<0.01$ \\
\hline & & & & & OS & $\mathrm{RCP}$ & 0.05 \\
\hline \multirow[t]{2}{*}{ O'Farrell et al. ${ }^{24}$} & \multirow[t]{2}{*}{ AC, SCC, others } & \multirow[t]{2}{*}{ cT3 } & \multirow[t]{2}{*}{157} & \multirow[t]{2}{*}{$82(52 \%)$} & OS & $\mathrm{RCP}$ & NS \\
\hline & & & & & OS & CAP & 0.02 \\
\hline Liu et al. ${ }^{14}$ & SCC & cT1-4 & 94 & $94(100 \%)$ & OS & $\mathrm{RCP}$ & $<0.01$ \\
\hline
\end{tabular}

$S C C$ squamous cell carcinoma, $A C$ adenocarcinoma, $n C R T$ neoadjuvant chemoradiotherapy, $c T$ clinical $\mathrm{T}$ stage, $y p T$ pathologic $\mathrm{T}$ stage after nCRT, DFS disease-free survival, LRFS local recurrence-free survival, DSS disease-specific survival, CRM circumferential resection margin, $C A P$ College of American Pathologists, RCP Royal College of Pathologists

${ }^{a}$ Multivariate analysis

method; Suttie et al. noted that the transhiatal approach resulted in significantly more CRM involvement compared with the transthoracic approach. ${ }^{22}$ Because the transthoracic approach is our standard method, we could disregard this potential confounding effect.

Three other studies assessed the value of the CRM in which only a part of the included patients received nCRT, again with conflicting results. ${ }^{23-25}$ Thompson et al. ( $n=240,52 \%$ nCRT) did not find a survival benefit, whereas Reid et al. ( $n=269,15,6 \%$ nCRT) found a significantly better DFS and OS in patients with a RCP R0 resection. $^{23,25}$ Farrell et al. ( $\left.n=157,52 \% \mathrm{nCRT}\right)$ found the CAP definition $(P=0.02)$ more prognostic for the OS than the RCP definition. ${ }^{24}$

As in patients treated with nCRT, the optimal CRM definition in surgically treated patients also is unclear. Two recent meta-analyses showed that both CRM definitions were associated with a poor survival, although the CAP criteria differentiated higher-risk groups. ${ }^{11,12}$ Moreover Chan et al. found that the CAP definition, based on the hazard ratio and subgroup analysis, had a prognostic advantage over the RCP criteria. ${ }^{12}$ Concordant to these results, we found that the optimal CRM cutoff value in the surgery-alone group, analyzed with the Akaike Information Criterion, was the CAP.

Beside the CRM, lymph node metastasis associated variables were important prognostic factors in this study; lymph node ratio $>0.2$ was independent prognostic for both 2-year DFS and LRFS in the surgery-alone group and $\mathrm{pN}$ stage was the only prognostic factor for 2-year DFS in the nCRT group. One meta-analysis, which underlined the importance of lymph node metastasis, indicated that nodal metastases appeared to negate the prognostic value of the
CRM. ${ }^{12}$ Moreover, the presence of lymph node metastases and an involved CRM indicated a more advanced-staged disease. $^{26}$ Another prognostic factor in surgery-alone patients was the tumor length, which is in correspondence with previously published data. ${ }^{27}$

Pultrum et al. assessed the optimal CRM in surgically treated patients using the area under the curve (AUC) analysis on receiver operating curves (ROC, which does not incorporate the time factor. ${ }^{2}$ A method that includes the time factor is the more complex time-dependent ROC method according to Heagerty et al. $^{28}$ For our limited explorative study, however, we prefer to use multivariate Cox regression analysis and suggest validating the results in a larger cohort.

\section{CONCLUSIONS}

This study showed that both definitions of a tumor-free CRM $(\mathrm{CAP}>0 \mathrm{~mm}, \mathrm{RCP}>1 \mathrm{~mm})$ were not prognostic for DFS in patients treated with nCRT. A free CRM according the CAP definition was prognostic for 2-year DFS in the surgery-alone group and an optimal CRM cutoff between 0.0 and 0.2 and at $0.3 \mathrm{~mm}$ in the surgeryalone and nCRT groups, respectively. These findings should be validated in a large, prospective study.

DISCLOSURE The authors have nothing to disclose.

OPEN ACCESS This article is distributed under the terms of the Creative Commons Attribution 4.0 International License (http:// creativecommons.org/licenses/by/4.0/), which permits unrestricted use, distribution, and reproduction in any medium, provided you give appropriate credit to the original author(s) and the source, provide a link to the Creative Commons license, and indicate if changes were made. 


\section{REFERENCES}

1. van Hagen P, Hulshof MC, van Lanschot JJ, et al. Preoperative chemoradiotherapy for esophageal or junctional cancer. $N$ Engl $J$ Med. 2012;366:2074-84.

2. Pultrum BB, Honing J, Smit JK, et al. A critical appraisal of circumferential resection margins in esophageal carcinoma. Ann Surg Oncol. 2010;17:812-20.

3. Mirnezami R, Rohatgi A, Sutcliffe RP, Hamouda A, Chandrakumaran K, Botha A, Mason RC. Multivariate analysis of clinicopathological factors influencing survival following esophagectomy for cancer. Int J Surg. 2010;8:58-63.

4. Rao VS, Yeung MM, Cooke J, Salim E, Jain PK. Comparison of circumferential resection margin clearance criteria with survival after surgery for cancer of esophagus. J Surg Oncol. 2012; 105:745-9.

5. Deeter M, Dorer R, Kuppusamy MK, Koehler RP, Low DE. Assessment of criteria and clinical significance of circumferential resection margins in esophageal cancer. Arch Surg. 2009; 144:618-24.

6. Dexter SP, Sue-Ling H, McMahon MJ, Quirke P, Mapstone N, Martin IG. Circumferential resection margin involvement: an independent predictor of survival following surgery for oesophageal cancer. Gut. 2001;48:667-70.

7. Griffiths EA, Brummell Z, Gorthi G, Pritchard SA, Welch IM. The prognostic value of circumferential resection margin involvement in oesophageal malignancy. Eur J Surg Oncol. 2006; 32:413-9.

8. Khan OA, Fitzgerald JJ, Soomro I, Beggs FD, Morgan WE, Duffy JP. Prognostic significance of circumferential resection margin involvement following oesophagectomy for cancer. $\mathrm{Br} \mathrm{J}$ Cancer. 2003;88:1549-52.

9. College of American Pathologists. Surgical Pathology Cancer Case Summary (Checklist): Esophagus. College of American Pathologists; Northfield, 2005.

10. Mapstone N. Minimum Dataset for Oesophageal Carcinoma Histopathology Reports (1st edn). Royal College of Pathologists: London, 1998.

11. Wu J, Chen QX, Teng LS, Krasna MJ. Prognostic significance of positive circumferential resection margin in esophageal cancer: a systematic review and meta-analysis. Ann Thorac Surg. 2014; 97:446-53.

12. Chan DS, Reid TD, Howell I, Lewis WG. Systematic review and meta-analysis of the influence of circumferential resection margin involvement on survival in patients with operable oesophageal cancer. Br J Surg. 2013;100:456-64.

13. Chao YK, Yeh CJ, Chang HK, et al. Impact of circumferential resection margin distance on locoregional recurrence and survival after chemoradiotherapy in esophageal squamous cell carcinoma. Ann Surg Oncol. 2011,18:529-534.

14. Liu CY, Wang BY, Lee MY, Tsai YC, Liu CC, Shih CH. The prognostic value of circumferential resection margin in esophageal squamous cell carcinoma after concurrent chemoradiation therapy and surgery. J Chin Med Assoc. 2013,76:570-5.
15. Harvin JA, Lahat G, Correa AM, et al. Neoadjuvant chemoradiotherapy followed by surgery for esophageal adenocarcinoma: significance of microscopically positive circumferential radial margins. J Thorac Cardiovasc Surg. 2012;143:412-20.

16. American Joint Committee on Cancer. AJCC cancer staging manual, 6th edn. New York: Springer; 2002.

17. American Joint Committee on Cancer. AJCC cancer staging manual, 7th edn. New York: Springer; 2009.

18. Muijs C, Smit J, Karrenbeld A, et al. Residual tumor after neoadjuvant chemoradiation outside the radiation therapy target volume: a new prognostic factor for survival in esophageal cancer. Int J Radiat Oncol Biol Phys. 2014;88:845-52.

19. Akaike $\mathrm{H}$. A new look at the statistical model identification. IEEE Trans Autom Control1974;19(6):716-23.

20. Verhage RJ, Zandvoort HJ, ten Kate FJ, van Hillegersberg R. How to define a positive circumferential resection margin in T3 adenocarcinoma of the esophagus. Am J Surg Pathol. 2011;35: 919-26.

21. Khan OA, Cruttenden-Wood D, Toh SK. Is an involved circumferential resection margin following oesphagectomy for cancer an important prognostic indicator? Interact Cardiovasc Thorac Surg. 2010;11:645-8.

22. Suttie SA, Nanthakumaran S, Mofidi R, Rapson T, Gilbert FJ, Thompson AM, Park KG. The impact of operative approach for oesophageal cancer on outcome: the transhiatal approach may influence circumferential margin involvement. Eur J Surg Oncol. 2012;38:157-65.

23. Thompson SK, Ruszkiewicz AR, Jamieson GG, et al. Improving the accuracy of TNM staging in esophageal cancer: a pathological review of resected specimens. Ann Surg Oncol. 2008;15: 3447-58.

24. O'Farrell NJ, Donohoe CL, Muldoon C, Costelloe JM, King S, Ravi N, Reynolds JV. Lack of independent significance of a close $(<1 \mathrm{~mm})$ circumferential resection margin involvement in esophageal and junctional cancer. Ann Surg Oncol. 2013;20:272733.

25. Reid TD, Chan DS, Roberts SA, Crosby TD, Williams GT, Lewis WG. Prognostic significance of circumferential resection margin involvement following oesophagectomy for cancer and the predictive role of endoluminal ultrasonography. $\mathrm{Br} J$ Cancer. 2012;107:1925-31.

26. Griffiths EA, Pritchard SA, Mapstone NP, Welch IM. Emerging aspects of oesophageal and gastro-oesophageal junction cancer histopathology: an update for the surgical oncologist. World $J$ Surg Oncol. 2006;4:82.

27. Eloubeidi MA, Desmond R, Arguedas MR, Reed CE, Wilcox CM. Prognostic factors for the survival of patients with esophageal carcinoma in the U.S.: the importance of tumor length and lymph node status. Cancer. 2002;95:1434-43.

28. Heagerty PJ, Lumley T, Pepe MS. Time-dependent ROC curves for censored survival data and a diagnostic marker. Biometrics. 2000;56:337-44. 